\title{
L'évolution de la protection du patrimoine au Japon depuis 1950 : sa place dans la construction des identités régionales
}

1950年からの日本文化財保護法の展開と地域アイデンティティの形成 The Evolution of Heritage Preservation in Japan since 1950 and its Role in Constructing Regional Identities

\section{Takashi Inada}

Traducteur : Laurent Nespoulous

\section{OpenEdition \\ Journals}

\section{Édition électronique}

URL : http://journals.openedition.org/ebisu/1576

DOI : 10.4000/ebisu.1576

ISSN : 2189-1893

\section{Éditeur :}

Institut français de recherche sur le Japon (UMIFRE 19 MAEE-CNRS), Maison franco-japonaise

\section{Édition imprimée}

Pagination : 21-46

ISSN : $1340-3656$

\section{Référence électronique}

Takashi Inada, «L'évolution de la protection du patrimoine au Japon depuis 1950 : sa place dans la construction des identités régionales », Ebisu [En ligne], 52 | 2015, mis en ligne le 20 septembre 2015, consulté le 19 avril 2019. URL : http://journals.openedition.org/ebisu/1576 ; DOI : 10.4000/ebisu.1576 


\section{L'évolution de la protection du patrimoine au Japon depuis 1950}

Sa place dans la construction des identités régionales

INADA Takashi

\begin{abstract}
\ Mots-clés : Loi sur la protection des biens culturels, biens culturels, patrimoine, archéologie préventive, décentralisation, identités régionales.

L'auteur : Inada Takashi est archéologue, professeur émérite à l'université d'Okayama. Il a dirigé de nombreuses fouilles et prospections centrées sur la faune fossile du Pléistocène. Il est aussi connu pour ses travaux comparatifs sur le Paléolithique au Japon, en France et en Afrique, ainsi que sur les différents systèmes de protection des biens culturels en Europe et au Japon.
\end{abstract}

Résumé : Au Japon, les premières dispositions modernes de conservation des biens culturels remontent à 1871 et la première loi de protection, au fondement des mesures actuelles, date de 1950 . Mais la forte croissance économique et la décentralisation d'après 1945, ainsi que la volonté de se conformer au système du Patrimoine mondial de l'Unesco, ont conduit à des évolutions substantielles dans la protection du patrimoine. La promotion des biens culturels toujours plus proches des populations locales, ainsi que l'instauration d'un système de déclaration a nécessité des arrangements qui amoindrissent la rigueur du cadre de protection. Toutefois, les "biens culturels enfouis", constituent l'exception qui n'a toujours pas de place claire au sein de la loi. 
ンキーワード

文化財、文化遺産、文化財保護法、事前考古学、 地方分権、地域アイデンティティ

\section{著者}

稲田孝司は岡山大学名誉教授。主に日本旧石 器時代の研究を進め、岡山県恩原遺跡群の発 掘調査や全国の更新世動物化石産地の試掘 ・ 発掘調査を実施してきた。また、日本とフラ ンス・アフリカ・中国その他諸地域における 旧石器文化の比較研究を行い、あわせて日本 とヨーロッパにおける遺跡保護に関する比較 研究も進めている。

\section{要旨}

日本に拈ける、近代的な文化財保護の はじまりは 1871 年にさかのぼり、現行法 の基礎となる最初の文化財保護法の成立は 1950 年である。しかし、戦後の経済成長や 地方分権の発展、あるいはユネスコの世界 遺産条約への加盟の影響を受け、文化財保 護のあり方はかなりの変化をみせてきた。 文化財をより地域に根ざしたものにしょうと する傾向および申告制度の創設により、保護 の枠組みをより柔軟にする必要性が生じた。 しかし、文化財保護法の文化財の定義の中で は「埋蔵文化財」がいまだに正当に位置づけ られていないという問題点も残っている。
Veywords: Law for the Preservation of Cultural Properties, Cultural Properties, Heritage, Preventive Archaeology, Decentralisation, Regional Identities.

The Author: Inada Takashi specialises in the Palaeolithic era and has led numerous excavations of Pleistocene fossils, including the Onbara site (Okayama Prefecture). He is also known for his comparative studies on the Palaeolithic era in Japan, France and Africa, as well as on European and Japanese systems to preserve cultural properties.

\begin{abstract}
The first modern measures to preserve Japan's cultural properties were taken in 1871, while the first preservation law, on which current measures are based, was passed in 1950. However, the strong economic growth and decentralisation that have characterised postwar Japan, as well as the desire to meet UNESCO World Heritage criteria, have led to substantial changes in heritage preservation. The promotion of cultural properties increasingly linked to the lives of local populations, in addition to the establishment of a notification system, has seen a move towards more flexible methods of protection. Nevertheless, the so-called "buried cultural properties" remain the exception that still has no clearly defined place in the law.
\end{abstract}




\section{L'évolution de la protection du patrimoine au Japon depuis 1950 \\ Sa place dans la construction des identités régionales}

INADA Takashi 稲田孝司*

Comme c'est le cas de bien des États-nations modernes créés dans le courant du XIX ${ }^{\mathrm{e}}$ siècle, le Japon se pose la question de la définition et du devenir de son patrimoine depuis sa refondation moderne.

La première expression, résolument moderne, de cette préoccupation prend forme le $5^{\mathrm{e}}$ mois de 1871 avec un décret "Pour la conservation des antiquités ${ }^{1}$ "du Dajōkan 太政官, le premier régime de gouvernement (1868-1885) qui ouvre l'ère Meiji. Le premier gouvernement de la Restauration de Meiji, soucieux d'asseoir une civilisation japonaise à la fois moderne et ancrée dans l'autochtonie, a fortement œuvré pour imposer le shintō comme religion d'État, contre la présence du bouddhisme et de son patrimoine architectural ancien considérés comme invasifs. Ainsi, dans les toutes premières années de l'ère Meiji, de nombreux objets et bâtiments japonais traditionnels ont été abandonnés, vendus, parfois même livrés à la folie destructrice de fanatiques. Ce n'est qu'à l'arrivée de Machida Hisanari

* Professeur émérite de l'université d'Okayama 岡山大学.

1. Littéralement décret pour la conservation des "vieux objets et anciennes choses ", Koki kyübutsu hozon kata 古器旧物保存方. Proclamation du $23^{\mathrm{e}}$ jour du $5^{\mathrm{e}}$ mois de l'an 4 de l'ère Meiji (1871), intitulée koki kyübutsu o hozen seshimu 古器舊物ᄏ保全セシム; fait partie des hörei 法令, décrets et proclamations de l'an 4 de Meiji. Une synthèse des lois relatives à la conservation et à la protection du patrimoine figure dans l'encadré infra. 
町田久成 (1838-1897) au poste de Daigaku taijo 大学大丞 ${ }^{2}$, en 1870, que cette politique est partiellement modifiée. Machida est un fonctionnaire originaire du fief de Satsuma qui, à la fin de l'époque d'Edo, se rend en Europe où il observe les dispositifs qui encadrent patrimoine et monuments historiques. Face aux destructions du début de l'ère Meiji, c'est lui qui, devenu haut fonctionnaire, propose au Dajōkan, en avril 1871, une politique pour la préservation des biens culturels et une première forme de musée national, le Shūkokan 集古館. Compte tenu du fait que cette mesure est imposée par le haut, nous pouvons parler ici d'une protection du patrimoine à la faveur d'un étatisme éclairé.

À partir de 1880, un "Fonds alloué aux anciens sanctuaires et temples " (Koshaji hozon-kin 古社寺保存金) est mis en place et permet de financer le grand recensement des textes, peintures, sculptures et autres objets d'art anciens dont sont dépositaires les établissements religieux. Cette grande entreprise conduit, en 1897, à la promulgation de la « loi de Conservation des anciens sanctuaires et temples " (Koshaji hozon-hō 古社寺保存法), dont la portée demeure toutefois réduite, puisqu'elle ne s'étend qu'aux objets possédés par les lieux de culte.

En 1898, le Japon se dote d'un Code civil. À sa suite, une loi spéciale sur les objets trouvés est promulguée en 1899 (Loi sur les objets trouvés, Ishitsubutsu-hō 遺失物法). Elle stipulait que toute découverte d'objets enfouis susceptibles d'avoir un intérêt archéologique, artistique ou scientifique doit être déclarée auprès des services de police. L'État émet alors une lettre d'instruction et prévient les services compétents : dans le cas d'objets liés aux tertres, le ministère du Palais (Kunai-shō 宮内省), responsable des tertres et mausolées impériaux ; dans le cas d'objets préhistoriques, l'université impériale de Tokyo. Ceux-ci font alors une sélection des documents jugés pertinents, qu'ils conservent.

Les destructions de sites - signes de modernité s'il en est - causées par l'aménagement et le développement du territoire, conduisent la Diète à adopter, en 1911, un "Projet de conservation des sites historiques et des monuments naturels" (Shiseki oyobi tennen kinenbutsu hozon ni kan suru kengian 史蹟及天然紀念物保存二関スル建議案). Cette réussite entraîne une

2. Haut fonctionnaire en charge de l'institution Daigaku 大学 qui allait devenir le ministère de l'Instruction publique, le Monbushō 文部省, en 1871. 
mobilisation citoyenne soutenue par l'Association pour la conservation des sites historiques, des lieux célèbres et des monuments naturels (Shiseki meishō tennen kinenbutsu hozon kyōkai 史蹟名勝天然紀念物保存協会), qui réunit historiens, botanistes, spécialistes de l'histoire de l'architecture, archéologues et membres de l'aristocratie de la fin de l'ère Meiji. Dans un contexte de glorification générale de la nation et de l'empereur, on peut aussi entendre des voix critiques comme celle de Minakata Kumagusu 南方 熊楠 (1867-1941). Ethnologue et botaniste, ce dernier emploie son énergie à protéger la flore de l'îlot de Kashima (dans la baie de Tanabe, département de Wakayama). Il est opposé à la politique, lancée en 1906, par l'État, qui vise à réduire le nombre de sanctuaires en les regroupant ${ }^{3}$. Il considère que la disparition des bois sacrés du territoire des villages va provoquer " la dissolution des communautés et constitue une menace pour leur autonomie de fonctionnement ", et qu'en effaçant les paysages du passé et les sites historiques qui s'y inscrivent, on provoque le déclin brutal des régions. Minakata aura à subir les pressions du régime pour ses opinions. En tant que défenseur des biens culturels et naturels pensés dans le cadre des identités régionales, il peut nous apparaître comme très moderne, mais il faut bien comprendre que dans la société de son époque, il est très isolé dans son combat.

C'est au terme de ces multiples péripéties qu'est enfin promulguée en 1919 la loi de Conservation des sites historiques, lieux célèbres et monuments naturels (Shiseki meishō tennen kinenbutsu hozon-hō 史蹟名勝天然 紀念物保存法). Cette loi élargit son champ d'application à un plus grand nombre de biens culturels, ainsi qu’à quelques éléments du patrimoine naturel. Toutefois, les biens qui font l'objet d'une protection - par une procédure de "classement " (on parle alors pour la première fois de shitei 指定) - de la part des institutions sont limités à ceux jugés les plus admirables. Quelques très rares sites archéologiques peuvent être classés en site historique, mais le patrimoine relevant de l'archéologie est, en règle générale, contrôlé par un autre dispositif. Celui-ci relevait des mesures fixées par

3. Politique initiée, en 1906, par le décret de regroupement des sanctuaires (Jinja $g o \bar{s} h i-r e i$ 神社合祀令), et poursuivie jusqu'en 1914. Elle fut appliquée de façon inégale à travers le pays, mais l'on estime que 70000 sanctuaires furent détruits sur les quelque 200000 que comptait l'archipel. 
deux circulaires émises respectivement en 1874 et en 1899, promulguant l'interdiction de fouiller sans autorisation les « anciens tertres ${ }^{4}$ » et l'obligation d'en déclarer l'éventuelle découverte, carte et croquis à l'appui. Ces dispositions visent à établir la présence des tombes des souverains légendaires mentionnés dans les textes antiques ainsi que la localisation des tombes associées à leur lignée, dans le but de répondre à une nécessité de l'époque : imposer une idéologie centrée autour de la figure de l'« empereur ». Dans le règlement d'application de la loi de 1919, toute découverte d'un nouveau tertre ou autre site doit faire l'objet d'une déclaration sous 10 jours auprès du préfet $^{5}$.

En 1929, la loi de Conservation des anciens sanctuaires et temples est réformée en loi de Conservation des trésors nationaux (Kokuhō hozon-hō 国宝保存法) et son champ d'application est élargi aux biens possédés par l'État, les départements ou même des individus. De 1930 à 1945, la question des biens culturels se recentre, pour les pouvoirs publics, de manière spectaculaire autour du classement des " traces sacrées du passage de l'empereur Meiji »(Meiji tennō seiseki 明治天皇聖跡) : ces dernières en viennent à constituer $40 \%$ (377 sites au total) de tout ce qui fait l'objet de classement en site historique. Bien loin des notions de valeur culturelle ou scientifique, c'est la domination idéologique caractéristique de cette période qui transparaît au travers de cette politique.

Dans le Japon vaincu d'après 1945, l'incendie, en 1949, du pavillon d'or du Hōryūjị ${ }^{6}$, déclenche de nouveaux débats à la Diète sur le devenir

4. Kofun 古墳 : tombes à tumulus édifiées durant la période Kofun, c'est-à-dire du milieu du III $^{\mathrm{e}}$ siècle jusqu'au viI ${ }^{\mathrm{e}}$ siècle.

5. Depuis le début de l'ère Meiji et jusqu'en 1946 sous occupation américaine, l'autorité de l'État dans les départements s'incarne dans un fonctionnaire nommé à cet effet : le préfet, chiji 知事 ou chihō chōkan 地方長官. Cette situation change après 1945, où il n'y a plus de préfet mais un représentant, sorte de gouverneur à l'américaine, toujours appelé chiji (le terme chōkan disparaît dans la mesure où il implique la notion de haut fonctionnaire de l'État) et qui a les mêmes pouvoirs (police, etc.), mais qui est élu par ses administrés. De ce fait, " préfet » et " préfecture " cessent d'exister dans le Japon d'aprèsguerre, bien qu'il soit encore abusivement fait référence (le plus souvent en anglais) aux départements japonais, ken 県, par le terme de "préfecture".

6. Le Hōryūji 法隆寺 est un complexe monastique bouddhique installé au viI ${ }^{\mathrm{e}}$ siècle à Ikaruga, dans le département de Nara. Il subit les affres des premières années de l'ère Meiji (voir supra), avant de faire l'objet de mesures de protection. Il est classé au 
de la protection du patrimoine. C'est ainsi qu'est adoptée, en 1950, la loi de Protection des biens culturels (Bunkazai hogo-hō 文化財保護法), toujours en vigueur de nos jours ${ }^{7}$. Cette loi reprend le contenu du cadre législatif d'avant-guerre : d'une part, la loi de Conservation de sites historiques, des lieux célèbres et des monuments naturels et, d'autre part, la loi de Conservation des trésors nationaux. En ce qui concerne les documents archéologiques, on voit apparaître la nouvelle notion de "biens culturels enfouis " (maizō bunkazai 埋蔵文化財 $)^{8}$ qui, somme toute, marque une continuité avec l'esprit du règlement d'application de la loi de 1919 et celui de la loi sur les objets trouvés de 1899 . On sait par ailleurs que les forces d'occupation alliées témoignent d'un certain intérêt pour ces questions de protection des sites, et il est bien possible que le Japon soit influencé par la situation en Europe au même moment (Inada 2014 : 296). C'est là une question encore peu étudiée qui mériterait de plus amples travaux. Une tendance à la réappropriation par les citoyens de leur patrimoine parcourt également la nouvelle loi élaborée en 1950. Pourtant, et c'est notable dans le cas du traitement de la documentation archéologique, la notion de bien culturel continue à être régie comme dans le cadre législatif ancien, sans faire l'objet des travaux de redéfinition qu'il aurait été légitime d'attendre. Si bien que l'on retiendra surtout que, à la différence du cadre strictement étatiste de gestion des biens culturels avant-guerre, tourné souvent vers la figure de l'empereur, l'après-guerre se caractérise par un ancrage plus marqué dans la population et les départements, dotés d'une plus grande autonomie.

De nos jours, plusieurs décennies plus tard, comment se présente la protection du patrimoine au Japon ? Comment envisager son avenir ? Il y a plusieurs manières de répondre à ces questions. Les médias, par exemple, se plaisent à focaliser leur attention sur des problèmes tels que le classement

patrimoine mondial de l'humanité depuis 1993. Sur le Hōryūji et sa valorisation au titre de patrimoine japonais, voir la contribution de B. Jacquet dans ce numéro.

7. On peut observer le glissement sémantique suivant : depuis l'ère Meiji et jusqu'avantguerre, il était toujours question de lois ou de réglementations de " conservation " (hozon 保存) ; après-guerre, dans un Japon encore largement dévasté, à partir de la loi de 1950, on parlera désormais de "protection" (hogo 保護).

8. Terme consacré depuis 1950 pour désigner les sites et les objets mis au jour et étudiés par l'archéologie, et tout particulièrement par l'archéologie préventive. 
du mont Fuji au patrimoine mondial de l'humanité ${ }^{9}$ ou la protection des peintures des chambres funéraires des tertres de Takamatsuzuka ou de Kitora $^{10}$. Il s'agit certes là de sujets parfaitement légitimes et importants, mais ils n'en demeurent pas moins d'une portée fort limitée, et détournent l'attention des enjeux fondamentaux de la gestion des biens culturels.

Le vrai questionnement qu'il convient de développer - celui qui recouvre l'ensemble des champs de la protection du patrimoine au Japon - a trait aux dynamiques des mesures décidées à l'échelon national. Ces dernières, impulsées par l'agence de la Culture (Bunkachō 文化庁), sont l'objet d'un constant débat entre chercheurs et pouvoirs publics, et se déploient selon deux axes principaux. L'un relève de la protection d'un patrimoine enraciné dans le quotidien des sociétés, de la protection d'un patrimoine "vivant "; l'autre a pour objet d'organiser la décentralisation - une gestion du patrimoine par et pour les régions - de la protection des biens culturels. Ces deux grandes tendances présentent, autant l'une que l'autre, une importance évidente pour la construction des identités régionales. Elles laissent néanmoins dans l'ombre la question de la protection des "biens culturels enfouis ", qui constituent pourtant l'un des gisements d'objets fondamentaux de l'élaboration du patrimoine.

9. Après une longue campagne à rebondissements (impossibilité d'un classement au titre de " patrimoine naturel " compte tenu de la mauvaise intégrité du site, dégradé notamment par la quantité de détritus laissés par les randonneurs) en vue de son classement, le Fuji est, depuis 2013, classé " patrimoine culturel mondial ».

10. Les tertres de Takamatsuzuka (Takamatsuzuka kofun 高松塚古墳) et de Kitora (Kitora kofun キトラ古墳), situés dans le département de Nara, près d'Asuka, sont datés d'entre la fin du viI ${ }^{\mathrm{e}}$ siècle et le début du viII ${ }^{\mathrm{e}}$ siècle. Takamatsuzuka, découvert en 1970 (mais pillé vraisemblablement au début du Moyen Âge), a fait l'objet de fouilles à partir de 1972, pour être finalement classé « site historique exceptionnel " (Tokubetsu shiseki 特別史跡) en 1973. Les parois nord, est, ouest et le plafond de la chambre funéraire sont peintes de décors - chose jusqu'alors inédite - très marqués par la culture de cour de la péninsule coréenne (et au-delà, de la Chine des Tang). Ces peintures ont été classées « trésor national " (kokuhō 国宝) en 1974. En 1983, Kitora devient le deuxième tombeau à présenter des peintures qui, comme celles de Takamatsuzuka, témoignent de l'influence culturelle de la péninsule à la fin du viI ${ }^{\mathrm{e}}$ siècle. Kitora est à son tour classé, en 2004, "site historique exceptionnel ». Ces deux tertres font depuis longtemps l'objet d'une abondante couverture médiatique. L'exposition des chambres funéraires et de leurs peintures à l'air et aux visiteurs, malgré un dispositif en atmosphère contrôlée, pose d'importantes difficultés de conservation. 
Notre contribution se propose de donner au lecteur les éléments de contextualisation nécessaires pour bien comprendre le dispositif légal et institutionnel de la protection des biens culturels au Japon. Il s'agira de poser les bases d'un questionnement qui portera, pour finir, sur la situation actuelle de la protection du patrimoine japonais et des défis qui lui sont lancés.

\section{Contenu et modifications de la loi de Protection des biens culturels}

C'est un fait bien connu au Japon, la loi de 1950 (entrée en vigueur le 24 décembre 1951) sur la protection des biens culturels, a subi de nombreuses modifications - les plus importantes en 1954, 1975 et 2004 - qui ont élargi son champ d'application.

- En 1950, l'article 2 stipulait l'existence de trois catégories constitutives de ce qu'il convenait de considérer comme "biens culturels": les «biens culturels matériels» (yükei bunkazai 有形文化財), les «biens culturels immatériels» (mukei bunkazai 無形文化財) et enfin, les "sites et monuments historiques, les paysages célèbres et les monuments - espèces - naturel(le)s" (shiseki meishō tennen kinenbutsu 史跡 名勝天然記念物).

- En 1954, cette dernière catégorie est prosaïquement renommée 《monuments " (kinenbutsu 記念物) et une quatrième catégorie, intitulée "documents folkloriques"(minzoku shiryō 民俗資料), voit le jour.

- En 1975, cette dernière catégorie est à son tour rebaptisée «biens culturels folkloriques " (minzoku bunkazai 民俗文化財) et une cinquième catégorie, intitulée "ensembles de bâtiments traditionnels " (dentōteki kenzöbutsugun 伝統的建造物群), est créée.

- Enfin, les modifications de 2004 élargissent la protection à une sixième catégorie, prenant en charge l'intégrité des "paysages culturels " (bunkateki keikan 文化的景観). C'est la loi révisée de 2004 qui constitue le cadre de protection en vigueur aujourd'hui.

Cet élargissement progressif se vérifie donc non seulement quantitativement par l'augmentation des catégories soumises à protection, mais également qualitativement, avec l'élargissement de la notion de bien culturel d'un statut mobilier (objet) vers un statut comprenant l'immobilier (bâtiment), 
La conservation et la protection des biens culturels et du patrimoine au Japon en quelques lois

1871 : Proclamation pour la conservation des antiquités Koki kyūbutsu hozon kata 古器旧物保存方.

1871 : Création du ministère de l'Instruction publique, le Monbushō 文部省.

1880 : Fonds alloué aux anciens sanctuaires et temples Koshaji hozon-kin 古社寺保存金.

1889 : Constitution de l'empire du grand Japon, en vigueur jusqu'en 1947.

1897 : Loi de Conservation des anciens sanctuaires et temples Koshaji hozon-hō 古社寺保存法.

1899 : Instauration du Code civil japonais.

1899 : Loi sur les objets trouvés, littéralement "Loi sur les biens perdus », Ishitsubutsu-hō 遺失物法.

1911: Projet de conservation des sites historiques et des monuments naturels Shiseki oyobi tennen kinenbutsu hozon ni kan suru kengian 史蹟及天然紀念物保存二関スル建議案.

1919 : Loi de Conservation des sites historiques, lieux célèbres et monuments naturels Shiseki meishō tennen kinenbutsu hozon-hō 史蹟名勝天然紀念物保存法.

1929 : Abrogation de la loi de 1897 et promulgation de la loi de Conservation des trésors nationaux Kokuhō hozon-hō 国宝保存法. 
1950 : Création du Comité de protection des biens culturels Bunkazai hogo iinkai 文化財保護委員会.

1950 : Loi de Protection des biens culturels Bunkazai hogo-hō 文化財保護法 (classe les catégories actuelles de " bien culturels » en : « biens culturels matériels » yūkei bunkazai 有形文化財; « biens culturels immatériels » mukei bunkazai 無形文化財; “sites et monuments historiques, paysages célèbres et monuments - espèces - naturel(le)s » shiseki meishō tennen kinenbutsu 史跡名勝天然記念物.

Révision de 1954 : " sites et monuments historiques, paysages célèbres et monuments - espèces - naturel(le)s » devient " monuments » kinenbutsu 記念物; introduction de la catégorie « documents folkloriques » minzoku shiryō 民俗資料; les « biens culturels enfouis » maizō bunkazai 埋蔵文化財 sont extraits de la catégorie " biens culturels matériels », et donc de la liste de définition des biens culturels, et placés dans le chapitre 4 de la loi qui leur est consacrée.

Révision de 1975 : « documents folkloriques » devient " biens culturels folkloriques» minzoku bunkazai 民俗文化財; introduction de la catégorie «ensembles de bâtiments traditionnels" dentōteki kenzōbutsugun 伝統的建造物群; introduction de la notion de "techniques de conservation des biens culturels » bunkazai no hozon gijutsu 文化財の保存技術.

Révision de 2004: introduction de la catégorie «paysages culturels » bunkateki keikan 文化的景観.

1968 : le Comité de protection des biens culturels devient l'agence de la Culture Bunka-chō 文化庁.

1992: Signature par le Japon de la Convention pour la protection du patrimoine mondial, culturel et naturel (Unesco). 
ou encore de l'élément isolé (une maison) à l'ensemble (un quartier). La diversification de la protection se traduit concrètement par une grande variété de modalités de reconnaissance des biens culturels. Cette situation a naturellement conduit à des ajustements relatifs aux contraintes d'application des réglementations et aux prérogatives échues aux collectivités et aux pouvoirs publics. Voici les évolutions les plus notables dans le cadre de la désignation des biens culturels :

1) «Biens culturels matériels": la loi stipule (art. 2) que ce terme désigne des " productions culturelles matérielles telles que les bâtiments, les peintures, les sculptures, les objets d'art et d'artisanat, les textes anciens possédant une grande valeur historique ou artistique pour notre pays (ainsi que les terrains ou autres biens immobiliers avec lesquels ils prennent leur valeur), de même que les documents archéologiques ou tout autre document historique ayant une grande valeur scientifique». "Documents archéologiques" ne désigne ici que les seuls objets et non les sites.

Les "biens culturels matériels " sont sanctionnés par trois désignations distinctes (chap. 3) : classement (shitei 指定) comme « trésor national»(kokuhō 国宝), classement comme «bien culturel important» (jūyō bunkazai 重要文化財) et inscription/enregistrement (tōroku 登録) en tant que "bien culturel matériel "(tōroku yūkei bunkazai 登録有形文化財).

- La mention ci-dessus de "tout autre document historique ", de même que le contenu de la parenthèse qui la précède relative aux terrains et autres biens immobiliers, sont des ajouts de la révision de 1975. Dans le premier cas, il s'agissait d'élargir la définition de la nature des documents méritant classement, et dans le deuxième, de stipuler l'importance de la protection des terrains pour mieux protéger les bâtiments et les biens immobiliers.

Il va sans dire que tout item relevant de la liste des biens susceptibles d'être classés n'est pas automatiquement protégé. Pour obtenir la dénomination de bien culturel, l’objet doit posséder " une grande valeur historique ou artistique pour notre pays ", ou bien "présenter un caractère indispensable à la compréhension des changements des us et coutumes de notre peuple ». Nous reviendrons plus loin sur ces critères. 
- Le classement en «trésor national » ou «bien culturel important » appelle des mesures de conservation draconiennes. L'inscription comme «bien culturel matériel enregistré » est une disposition plus légère, instituée en 1996 lors d'une révision partielle de la loi, à destination des bâtiments, et qui touche, depuis 2004, les objets d'art et d'artisanat.

2) «Biens culturels immatériels» (art. 2) : le terme désigne " des productions culturelles intangibles, telles que les arts de la scène, la musique ou encore des savoir-faire artisanaux ».

Cette catégorie est sanctionnée (chap. 4) par un classement en «bien culturel immatériel important " (jūyō mukei bunkazai 重要無形 文化財) et par une reconnaissance (nintei 認定) en 《individu ou groupe détenteur d'un bien culturel immatériel» (jūyō mukei bunkazai no hojisha mata wa hoji dantai 重要無形文化財の保持者 又は保持団体).

Le classement et la reconnaissance d'un individu remontent à la loi de 1954, alors que l'élargissement à un groupe a été introduit par la révision de 1975 .

3) «Biens culturels folkloriques » (art. 2) : le terme s'applique à «des pratiques alimentaires, vestimentaires et d'habitat, des manifestations sociales, religions, croyances, évènements qui rythment l'année, arts et savoir-faire populaires, ainsi qu'à tous les vêtements, ustensiles et bâtiments concernés. "

Cette catégorie est sanctionnée (chap. 5) par un classement en "bien culturel matériel folklorique important " (jūyō yūkei minzoku bunkazai 重要有形民俗文化財), en «bien culturel immatériel folklorique important" (jūyo mukei minzoku bunkazai 重要無形民俗 文化財) et une inscription en tant que «bien culturel matériel folklorique enregistré »(tōroku yükei minzoku bunkazai 登録有形民俗 文化財).

- Dans la loi de 1950, la mention de « document folklorique » était employée dans le cadre des divers éléments du patrimoine matériel. C'est en 1954 que ce terme vint définir une catégorie autonome, en même temps qu'était institué le classement en "document folklorique matériel important " (yūkei no jūyō minzoku shiryō 有形の重要 民俗資料). Ce label est renommé, en 1975, «bien culturel matériel folklorique important». Alors qu'en 1954 le terme de "document 
folklorique immatériel » renvoyait à un ensemble de dispositions visant à l'enregistrement de pratiques folkloriques, la révision de 1975 institue clairement le classement en «bien culturel immatériel folklorique important». La révision de 2004 ajoutera la notion de "savoir-faire populaire » (minzoku gijutsu 民俗技術) et l'inscription de «bien culturel matériel folklorique enregistré ».

4) "Monuments" : la loi donne une acception très large à ce terme puisqu'il désigne (art. 2) «les sites archéologiques comme les amas coquilliers, les tertres, les vestiges des anciennes capitales, châteaux ou anciennes résidences aristocratiques ", mais également " des lieux célèbres tels certains jardins, ponts, gorges, bords de mer, chaînes de montagne ». Font également partie de cette catégorie "des animaux (habitat, lieu de reproduction, lieu de chasse inclus), des plantes (et leur niche écologique), certaines formations géologiques (y compris les terrains où sont répertoriés des phénomènes naturels particuliers)».

La nomenclature qui s'applique en cas de classement est la suivante (chap. 7) : « site historique exceptionnel »(tokubetsushiseki特別史跡), 《sitehistorique »(shiseki史跡), « lieu célèbre exceptionnel »(tokubetsu $m e i s h \bar{o}$ 特別名勝), “ lieu célèbre » (meishō 名勝), « monument naturel exceptionnel»(tokubetsu tennen kinenbutsu 特別天然記念物), " monument naturel " (tennen kinenbutsu 天然記念物).

Cette catégorie n'a pas connu d'évolution depuis l'adoption de la loi et se caractérise donc par un cadre de référence très stable.

5) «Paysage culturel » (art. 2) : il s'agit de "paysages formés par le mode de vie et l'activité des sociétés dans leur lieu de vie ou par un milieu particulier». Ces paysages sont sanctionnés (chap. 8) par une « sélection» (sentei 選定) en “ paysage culturel important ( jūyō bunkateki keikan 重要文化的景観).

6) «Ensemble de bâtiments traditionnels » (art. 2) : ce terme désigne des « regroupements de bâtiments et leur environnement immédiat dont l'intégrité a valeur de témoignage historique». Il s'agit donc de quartiers ou de zones qui font l'objet d'une sélection (chap. 9) en "zone importante de conservation de bâtiments traditionnels" (jūyō dentōteki kenzōbutsugun hozon chiku 重要伝統的建造物群保存 地区). 
À ces différentes catégories explicitées dans l'article 2, les chapitres 6 et 10 ajoutent d'autres éléments devant faire l'objet d'une protection : les "biens culturels enfouis ", évoqués plus haut, et les " techniques de conservation des biens culturels »(bunkazai no hozon gijutsu 文化財の保存技術).

Laissons pour l'instant de côté les premiers. La question des techniques de conservation des biens culturels est introduite par la révision de 1975, dans laquelle elle fait l'objet d'une attention particulière (chap. 5-3), mais n'est pas définie dans l'article 2. Dans le texte actuellement en vigueur, c'est l'article 147 du chapitre 10 qui stipule que "l'on pourra considérer comme "technique sélectionnée de conservation" (sentei hozon gijutsu 選定保存技術), toute technique ou compétence technique traditionnelle - ainsi que le cadre qui garantit son existence le cas échéant - indispensable à la conservation d'un bien culturel ». Dans ce cas précis, il ne s'agit donc pas de désigner la protection d'un bien culturel proprement dit, mais d'assurer la pérennité de "techniques ou de compétences techniques traditionnelles", ainsi que "du cadre qui garantit leur existence ", en instaurant une désignation en "technique sélectionnée de conservation". À cette caractérisation des savoir-faire correspond également une reconnaissance en "personne ou groupe détenteur de techniques sélectionnées de conservation" (sentei hozon gijutsu no hojisha mata wa hozon dantai 選定保存技術の保持者又は保存団体).

\section{La protection des « biens culturels vivants »}

Document s'appuyant sur l'ordonnance du Cabinet de 2002 fixant « la politique générale de promotion des arts et de la culture " (bunka geijutsu no shinkō ni kansuru kihontekina hōshin 文化芸術の振興に関する基本的な 方針), la circulaire du vice-secrétaire d'État à la culture du 27 décembre 2004, relative à la réforme de la loi de Protection des biens culturels, formule comme objectif «la mise en place d'un système de protection des biens culturels adapté aux transformations de la société ». Elle préconise :

1) la prise en compte de "davantage de formes de productions culturelles étroitement liées à la vie quotidienne des citoyens ";

2) un élargissement de la protection "à des biens culturels contemporains et au cadre qui permettrait leur conservation et leur valorisation "; 
3) la "diversification des modes de protection » venant accompagner cet élargissement du champ d'application.

Ce sont ces directives qui ont conduit, dans la révision, à l'ajout de la catégorie " paysage culturel ", à l'élargissement du patrimoine folklorique aux "savoir-faire populaires", et qui ont permis d'étendre la pratique de "l'inscription » de monuments ou de biens culturels matériels folkloriques, moins contraignante que celle du « classement».

À côté de l'expression relativement vague de "productions culturelles étroitement liées à la vie quotidienne des populations" (kokumin no seikatsu ni missetsu ni kanren shita bunkatekina shosan 国民の生活に密接 に関連した文化的な所産), on parle également de «biens culturels proches du quotidien des citoyens" (kokumin seikatsu ni mijikana bunkazai 国民 生活に身近な文化財) ou encore de 《biens culturels vivants" (ikiteiru bunkazai 生きている文化財) (Bunkachō dentō bunka-ka [Direction de la culture traditionnelle de l'agence de la Culture] 2004). Il s'agit là d'appellations qui ont pour but de marquer la protection des bâtiments, paysages et terres dans et sur lesquels vivent les gens de nos jours. La protection de ce type de patrimoine n'a pourtant pas commencé avec la révision de 2004. On pouvait déjà en voir des éléments précurseurs dans la sauvegarde du patrimoine naturel ou des lieux célèbres, protection qui passait par un système de restriction, d'autorisation et de mesures de gel des projets d'aménagement. La révision de 1975 instaurait déjà, par un système de déclaration de travaux, avis et mises en garde, la protection des biens culturels immatériels folkloriques importants, ou bien encore celle des zones de conservation de groupes de bâtiments traditionnels.

Le terme de «bien culturel " renvoie exclusivement à ce que la loi de Protection des biens culturels désigne expressément comme tel. Quand il s'agit d'évoquer des biens échappant aux définitions strictes de la loi, il est alors plus généralement question de " patrimoine culturel " (bunka isan 文化遺産) ou de “patrimoine historique»(rekishi isan 歴史遺産). Nous pouvons donner ici comme exemple la Loi relative aux dispositions spéciales sur la conservation des quartiers historiques des anciennes capitales (Koto ni okeru rekishiteki füdo no hozon ni kan suru tokubetsu sochi-hō 古都における歴史的風土の保存に関する特別措置法) de 1966, ou une autre loi similaire de 1980, portant cette fois-ci sur la conservation «du cadre historique d'Asuka et l'aménagement de son territoire" (Asuka-mura ni okeru rekishiteki füdo no hozon oyobi seikatsu kankyō no seibi tō ni kan suru 
tokubetsu sochi hō 明日香村における歷史的風土の保存及び生活環境の整備等 に関する特別措置法). La première s'intéressait aux villes antiques et médiévales de Nara, Kyoto et Kamakura, la deuxième se préoccupait d'un secteur du département de Nara où s'était formé, au viI ${ }^{e}$ siècle, le premier État japonais. Les surfaces à préserver étaient fort étendues et il s'agissait de mesures de protection relativement peu contraignantes - quoiqu'efficaces comparées au strict système de classement de la loi de Protection des biens culturels. Si l'on pousse la comparaison plus loin, il est évident que ces deux lois patrimoniales semblent s'intéresser à des objets bien précis et limités, là où la catégorie de "paysage culturel " de la loi sur les biens culturel a une valeur et une application générales pour tout le territoire.

Il est donc, certes, possible de saisir la notion de " paysage culturel » dans le prolongement de l'histoire plus ancienne de la protection du " patrimoine culturel vivant" au Japon, mais il faut bien observer que son sens et son implication sont d'un tout autre niveau. En outre, il ne fait aucun doute que le contexte de désignation de ces "paysages " est à mettre en relation directe avec les nouvelles préoccupations liées à l'inscription au patrimoine mondial de l'humanité de l'Unesco. Le Japon est un signataire relativement récent (depuis 1992) de la Convention pour la protection du patrimoine mondial, culturel et naturel, mais c'est justement cette année-là que le comité responsable, réuni en sa $16^{\mathrm{e}}$ session ordinaire, décide la promotion accrue des paysages culturels. L'inscription, en 1995, des rizières en terrasses des cordillères des Philippines, au titre de " patrimoine culturel vivant essentiellement évolutif ", a un fort retentissement au Japon : peu après (2000-2003), l'agence de la Culture commande une "Étude relative à la protection des paysages culturels liés aux activités de productions agraires, forestières et aquatiques " (Bunkachō kinenbutsu-ka [Direction des monuments de l'agence de la Culture] 2005). Cette étude a ensuite servi les propos de la révision de 2004 de la loi de Protection des biens culturels, lorsqu'il fallut définir la nouvelle catégorie de " paysage culturel ».

Les biens culturels immatériels entrent également dans la grande famille $\mathrm{du}$ " patrimoine vivant ». L'histoire de leur protection commence au Japon avec la loi révisée de 1954 et la reconnaissance des détenteurs d'un bien culturel immatériel important par la certification en "trésor national humain " ningen kokuhō 人間国宝). La position de l'Unesco avec, d'abord, en 1988, la " Proclamation des chefs-d'œuvre du patrimoine oral et immatériel de l'humanité ", puis, en 2003, la "Convention pour la sauvegarde 
du patrimoine culturel immatériel » (effective à partir de 2006), fait encore évoluer cette préoccupation.

Dans la situation actuelle, il n'est pas très risqué de conjecturer que des usines ou des machines utilisées de nos jours en viendront à être intégrées à la notion de patrimoine vivant. L'archéologie industrielle (sangyō kōkogaku 産業考古学), en tant que domaine s'intéressant aux installations de production, désigne déjà ce genre de vestige au moyen de l'expression " patrimoine industriel en état de fonctionnement " (dans ce cas précis kadō isan 稼働 遺産 en japonais, operated heritage en anglais). À cet égard, en mai 2012, une ordonnance du Cabinet a été émise "Sur la promotion des installations industrielles en vue de leur enregistrement au patrimoine mondial " (Kadō shisan o fukumu sekai isan tōroku ni mukete suisen suru baai no toriatsukai ni tsuite 稼働資産を含む世界遺産登録に向けて推薦する場合の取り扱いについて) qui place le patrimoine industriel sous la juridiction du Secrétariat général du gouvernement. Cela a amené la prise en compte des grands ensembles de Kyūshū et de Yamaguchi, très importants dans l'histoire de l'industrialisation du Japon ${ }^{11}$. Ces sites sont d'ailleurs l'objet de tensions : alors que l'agence de la Culture avait recommandé, en date du 23 août 2013, la candidature au patrimoine mondial, à l'horizon 2015, des églises chrétiennes de Nagasaki ${ }^{12}$, le gouvernement a préféré soutenir la recommandation émise, en septembre 2013, par le Secrétariat général du gouvernement sur la candidature du patrimoine industriel à Kyūshū et à Yamaguchi, dossier renommé pour l'occasion "patrimoine de la révolution industrielle durant l'ère Meiji au Japon ".

Une intrusion aussi nette du politique, depuis 2012 jusqu'à la remise des candidatures japonaises auprès de l'Unesco pour les inscriptions au patrimoine mondial en 2015, est sans précédent. Ces manœuvres ont fait naître de lourds soupçons quant à un calcul politicien contre l'agence de la Culture, jusque-là la seule institution légitime sur ces questions. En effet, compte tenu des évolutions et aménagements progressifs de la loi de Protection des biens culturels en matière de patrimoine vivant, cette

11. Déjà inscrits sur la liste indicative de l'Unesco dès 2009 au titre de "sites du patrimoine industriel moderne".

12. "Églises et sites chrétiens de Nagasaki » figurait sur la liste indicative de l'Unesco depuis 2007. 
dernière était parfaitement outillée pour répondre aux besoins et à la promotion du patrimoine industriel. Il n'y avait donc aucune utilité d'intérêt général à confier l'unique question du " patrimoine de la révolution industrielle de l'ère Meiji » au Secrétariat général du gouvernement.

\section{La protection du patrimoine culturel et les régions}

Ces problèmes de sélection en vue de l'Unesco découlent, d'une part, des nouvelles dispositions qui, depuis 2014, limitent le dépôt de candidatures à une par pays et, d'autre part, de la compétition acharnée à laquelle se livrent les régions désireuses d'obtenir l'enregistrement de leur patrimoine local au prestigieux échelon mondial. Pour ne rien arranger, en 2006 et 2007, l'agence de la Culture a procédé à une vaste opération de recueil de candidatures auprès des autorités départementales, laquelle a débouché sur la sélection de 12 dossiers, désormais inscrits à la liste indicative de l'Unesco. Chacun de ces dossiers est porté par un ou plusieurs départements. Les autorités impliquées, jusqu'aux plus petites municipalités, voient dans la réussite de leur candidature tant un enjeu de fierté locale qu'une probable source de revenus liés au tourisme, et usent de toutes les armes à leur disposition pour influencer le gouvernement à un niveau institutionnel ou politique afin d'obtenir son soutien.

Quoi que l'on puisse penser de cette compétition, il est indiscutable que la protection du patrimoine au Japon s'appuie massivement sur les collectivités locales. Certes, c'est l'agence de la Culture qui a fait avancer la cause du patrimoine vivant, mais ce sont bien les collectivités locales qui se chargent concrètement de toute la mise en œuvre des dispositifs qui la concernent.

Par exemple, les zones de conservation de bâtiments traditionnels sont délimitées dans le cadre du plan d'urbanisme des collectivités locales ou toute éventuelle réglementation décidée à leur niveau. C'est alors sur demande de ces dernières que l'agence de la Culture va retenir ou non les dossiers de candidature et labelliser ces secteurs en "zone importante de conservation de bâtiments traditionnels ». En décembre 2013, 106 zones, représentant 3733 hectares, étaient ainsi estampillées par l'agence, impliquant de fait 41 départements (sur 47) et 86 municipalités. 
Pour les paysages culturels, ce sont les municipalités qui, par leur réglementation sur l'urbanisme et le paysage, décident des mesures de protection. À nouveau, l'agence de la Culture examine alors toute candidature qui lui est adressée et décide de la désignation en " paysage culturel important ». En septembre 2011, on recensait 38 paysages culturels retenus par l'agence, pour 21 départements et 34 municipalités concernés.

La loi de 2008 sur la valorisation historique des villes (loi de Maintien ou d'Amélioration de l'intégrité historique des paysages dans les régions, Chiiki ni okeru rekishiteki füchi no iji oyobi kōjō ni kan suru hōritsu 地域における歴史的風致の維持及び向上に関する法律) relève de la juridiction conjointe du ministère des Transports, du ministère de l'Éducation et de la Recherche (agence de la Culture) et du ministère de l'Agriculture, des Eaux et forêts et de l'Industrie. Ce sont pourtant les municipalités qui sont chargées, y compris dans le cas des biens culturels classés ou retenus par l'agence de la Culture, de planifier l'application de cette loi. Dans les cas de planifications réussies, l'État reconnaît la conformité à la loi, ce qui déclenche un soutien à l'aménagement de l'" environnement historique " concerné (gestion et restauration des bâtiments importants, réglementation et respect d'une charte environnementale sur les panneaux publicitaires, les enseignes, etc.) et une aide financière publique. Les interactions attendues ne se limitent pas qu'aux municipalités, mais s'étendent également à des comités de résidents locaux ou à des associations à but non lucratif. En juin 2012, on pouvait compter 35 municipalités recevant l'agrément prévu dans le cadre de cette loi.

Afin d'assurer la protection des biens culturels vivants, il est indispensable d'obtenir le soutien et la compréhension des populations locales qui devront se plier aux diverses réglementations dans le cadre de leur vie quotidienne. Une relation étroite entre les services publics locaux et les habitants est souhaitable. Autant dire que, sans les collectivités locales, il ne peut y avoir de protection des biens culturels vivants. La réussite des mesures prônées par l'agence de la Culture dépend de ces collectivités. En ce sens, on ne soulignera jamais assez la force de l'impact de la loi sur la décentralisation de 1999 (Loi relative à la préparation de la décentralisation des pouvoirs, Chihō bunken no suishin o hakaru tame no kankei höritsu seibi tō ni kan suru hōritsu 地方分権の推進を図るための関係法律整備等に関する法律). 


\section{Les biens culturels enfouis, une anomalie au sein de la loi de Protection des biens culturels?}

Ce sont les biens culturels enfouis qui ont le plus fortement été touchés par les politiques de décentralisation. Les prérogatives en matière d'autorisation de fouille ou la responsabilité finale sur les objets découverts relèvent désormais des comités éducatifs territoriaux ${ }^{13}$ et non plus de l'agence de la Culture. Dans les faits, depuis 1970, les collectivités locales étaient déjà chargées tant des diagnostics devant évaluer la menace faite aux vestiges archéologiques par les travaux d'aménagement (et des négociations avec les aménageurs), que de la conduite des fouilles préventives elles-mêmes. La politique de décentralisation peut, en ce sens, n'apparaitre que comme une simple mise en accord de la loi avec la situation en cours.

Tout bien culturel enfoui (site archéologique) qui est menacé de destruction par des travaux doit faire l'objet de fouilles à la charge de l'aménageur : c'est le principe du "casseur, payeur ». Ainsi, 1997 a constitué l'année de tous les records avec 132,1 milliards de yens (6 milliards de francs de l'époque) de dépenses dédiées à l'archéologie préventive, tandis que 2011 a vu cette somme baisser à 52,3 milliards de yens (480 millions d'euros de l'époque). Rapporter ces sommes au budget total de l'agence de la Culture pour ces deux années, respectivement 82,8 et 90,9 milliards de yens ( 4 milliards de francs et 830 millions d'euros), permet de saisir l'importance des dépenses consenties pour les fouilles.

En 2000, un pic en matière de personnel avait été atteint avec 7111 personnes (titulaires des services publics ou vacataires) spécialisées dans la fouille de terrain. Cet effectif était retombé, en mai 2012, à 5968 personnes.

Les biens culturels enfouis relèvent de la compétence des archéologues professionnels, qui ne s'occupent pas exclusivement des sites archéologiques, mais qui sont également très au fait du patrimoine culturel et

13. Ces comités éducatifs (kyōiku iinkai 教育委員会) peuvent êtres départementaux, municipaux, cantonaux, et constituent un élément central du maillage de la décentralisation et de l'autonomie des pouvoirs publics (différentes formes de fonction publique territoriale). Ils font autorité dans l'application de tout ce qui relève de l'éducation et de la culture : archéologie préventive, protection et valorisation du patrimoine, politique éducative pour l'enseignement obligatoire (gestion de bibliothèques, gestion des écoles, de leur personnel, du contenu des enseignements, etc.). 
historique des collectivités et des services publics au sein desquels ils sont en poste. Par conséquent, les archéologues sont également impliqués, directement ou indirectement, dans la mise en œuvre des mesures relatives aux six catégories de biens culturels dont l'agence de la Culture a fixé la protection (art. 2 de la loi de Protection des biens culturels). Par exemple, à Uji, où se trouve le pavillon du Byōdōin ${ }^{14}$, une section de valorisation du patrimoine historique de la ville a été créée, en 2009, au sein du département de l'Aménagement dépendant du bureau du maire. C'est un archéologue des services des biens culturels enfouis du comité éducatif de la ville qui fut chargé du dossier " Paysage culturel d'Uji » en vue de sa reconnaissance comme paysage culturel important ${ }^{15}$. Dans les faits, à l'intérieur du dispositif décentralisé de gestion du patrimoine, les archéologues constituent un des éléments clés de l'application de ce que l'agence de la Culture cherche à promouvoir par sa loi de protection en matière de biens culturels vivants.

On ne manquera pas de remarquer l'étrangeté dudit dispositif vis-àvis des biens culturels enfouis. L'histoire de leur protection commence en même temps que la promulgation de la loi de Protection des biens culturels. Cette dernière, qui fixe donc le cadre de l'archéologie préventive au Japon, est détaillée en 17 articles au sein du chapitre 6 du texte actuellement en vigueur. Son déploiement systématique se fait, via le très dense maillage des collectivités locales, à une échelle véritablement gigantesque, à laquelle correspondent des ressources humaines non moins imposantes. Pourtant, il n'est aucunement fait mention des biens culturels enfouis dans l'article 2, qui a pourtant vocation de fixer le cadre de définition. Ce qui revient à dire qu'ils ne constituent pas une des six catégories de biens culturels reconnues par la loi. C'est la raison pour laquelle, lorsque l'agence de la Culture doit présenter un organigramme des éléments qui relèvent de sa compétence, elle place les biens culturels enfouis en dehors de ces six catégories

14. Le Byōdōin 平等院, édifié au milieu du $\mathrm{XI}^{\mathrm{e}}$ siècle, est un des bâtiments emblématiques de l'architecture antique japonaise, à tel point qu'il est régulièrement représenté, depuis 1950, sur les timbres, monnaies ou billets (ses bâtiments figurent sur les pièces de 10 yens depuis 1951 et l'un des deux phénix qui ornent le faîte de sa toiture est sur les billets de 10000 yens depuis 2004), et classé au patrimoine mondial, depuis 1994, au titre des Monuments historiques de Kyoto.

15. L'auteur tient à remercier Sugimoto Hiroshi 杉本宏, des services du patrimoine de la ville d'Uji, pour cette information. 


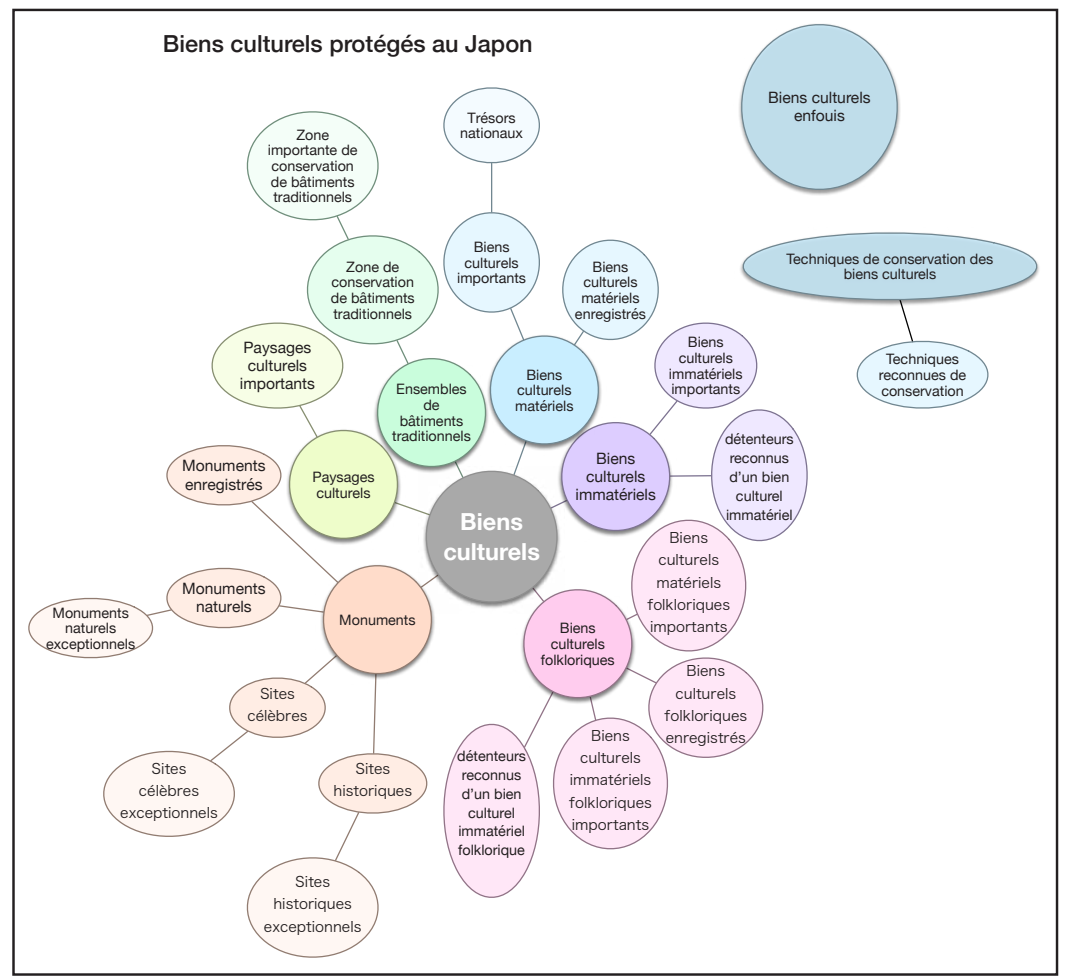

Fig. 1

Organigramme des biens culturels protégés au Japon

et les situe à côté des "techniques de conservation des biens culturels » (voir organigramme, fig. 1). L'article 2 comporte donc un sérieux défaut puisqu'il ne dit pas clairement si les biens culturels enfouis relèvent ou non de la catégorie des "biens culturels». Comment un tel vide de définition a-t-il pu survenir ?

Dans la loi de 1950, les "biens culturels enfouis " constituent la première occurrence de la section 2 «Biens culturels matériels autres que les "biens culturels importants" ", au sein du chapitre 3 "Biens culturels matériels». Il s'agit bien là d'une définition explicite. Lors de la révision de 1954, les « biens culturels enfouis " gagnent leur indépendance en un chapitre 4, intitulé d'après eux. Il serait alors naturel qu'ils fassent l'objet d'une définition au sein de l'article 2, mais il n'en est rien. Dans la mesure où 
ce traitement diffère de celui des "documents folkloriques », qui eux font l'objet d'une définition au titre d'une toute nouvelle catégorie, on peut en déduire qu'omettre les biens enfouis est un choix délibéré.

Une circulaire du 22 juin 1954, adressée par le chef de la Commission pour la protection des biens culturels (Bunkazai hogo iinkai 文化財保護委員会, " ancêtre " de l'agence de la Culture, fondée, elle, en 1968) aux directeurs des comités éducatifs départementaux, tente d'expliquer ces changements, sans pour autant apporter de raison à cette absence de définition dans l'article 2. Intitulée "Au sujet de la révision partielle de la loi de Protection des biens culturels" (Bunkazai hogo-hō no ichibu kaisei ni tsuite 文化財 保護法の一部改正について), la circulaire explique ainsi que «les "biens culturels" enfouis ne sont pas exclusivement matériels, ils peuvent être de nature folklorique, voire entrer dans la catégorie des "monuments", tels les amas coquilliers ou les vestiges de bâtiments; en raison de la variété d'objets qu'ils concernent, les biens culturels enfouis sont ainsi désormais régis dans le chapitre 4 qui leur est exclusivement consacré ».

Spécialiste de la jurisprudence du secteur culturel, Shiina Shintarō 椎名慎太郎 considère que cette lacune dans l'article 2 " écarte, de fait, les biens enfouis du dispositif principal de protection des biens culturels et que, sur ce point, le fondement juridique de cette mesure de protection constitue une anomalie ». Shiina explique cette situation par 1) le fait qu'en matière de patrimoine enfoui on ne sait jamais a priori ni le périmètre ni l'ampleur que devra prendre la protection ; 2) le fait que tant que le bien est enfoui, on n'en connaît ni la nature ni la valeur; et 3) le fait que « la loi est fondamentalement construite en partant des problèmes posés par le "bien culturel enfoui" considéré comme "artefact" "(Shiina 1977 : 220). Cette analyse critique donc le législateur, qui provoque une anomalie en considérant le bien culturel enfoui en tant qu'objet, alors qu'il suffirait de le saisir par le biais, par exemple, du terme de gisement archéologique.

Certes, cette lecture se tient parfaitement du point de vue du juriste. Pourtant, plutôt qu'une anomalie induite par une acception limitée de la terminologie applicable aux biens enfouis, on peut aussi voir dans cette disposition de la Commission pour la protection des biens culturels une décision calculée de laisser un flottement dans la loi. La modification la plus importante à ce sujet introduite par la révision de 1954 était l'obligation faite aux aménageurs (art. 57-2 ; aujourd'hui art. 93) de déclarer 
tous les travaux touchant "des terrains connus pour renfermer des biens culturels ». Dans la circulaire évoquée plus haut, il est dit que «l'essentiel de l'article 57-2 tient aux dispositions qu'il fixe pour permettre d'intervenir par des fouilles archéologiques avant la destruction consécutive aux travaux de terrassement, ou pendant les travaux eux-mêmes, afin d'éviter la dispersion des objets archéologiques mis au jour, de manière à ce que, autant que faire se peut, les sites puissent être sauvegardés au moins sous la forme d'un enregistrement des données qu'ils contiennent ». Ce dispositif prend en compte l'inéluctabilité de la destruction de nombreux sites, occasionnée par l'aménagement du territoire. Il s'agit donc sans doute d'une volonté de placer la protection des biens culturels enfouis dans un système de déclaration des travaux, anticipant la destruction ou l'accompagnant, par opposition à un système d'autorisation très rigide propre à l'article 2 .

\section{En guise de conclusion}

Les modifications apportées ces dernières années à la loi de Protection des biens culturels et aux politiques de l'agence de la Culture ciblent plus que jamais la protection de biens culturels proches des populations et de leur quotidien. La sauvegarde du patrimoine a donc connu une transformation profonde qui l'inscrit dans un cadre de protection pensé par et pour les régions elles-mêmes. Il s'agit d'un système tout à fait différent de celui, imaginé dès avant-guerre, de protection très stricte d'un nombre limité de biens culturels considérés comme exceptionnels. Il ne fait aucun doute que la protection du patrimoine au Japon est désormais l'objet d'une profonde modernisation. Elle cherche à se conformer aux standards internationaux et, à l'intérieur du pays, à encourager la construction d'identités localement inscrites. Les initiatives d'aménagement des villes autour du patrimoine culturel sont caractérisées par une grande variété de formes, et le cadre de la protection, dans ce nouveau contexte, est caractérisé par sa grande flexibilité (déclaration, enregistrement).

Le patrimoine enfoui est présent dans toutes les régions et constitue un des éléments les plus mis à contribution dans la construction des identités régionales. En outre, les modes de protection qui lui sont appliqués, qui passent toujours d'abord par la notification de travaux à venir, sont, 
quasiment depuis les débuts de la protection des biens culturels au Japon, d'une grande flexibilité. Un rapport de la Commission d'enquête sur les conditions de réalisation des fouilles préventives (fondé en 2007 par l'agence de la Culture), intitulé Le Patrimoine enfoui, sa conservation et sa valorisation. Pour une administration des biens culturels enfouis centrée sur l'autonomie et le dynamisme des régions et de leurs populations (Maizō bunkazai no hozon to katsuyō. Chiikizukuri, hitozukuri o mezasu maizō bunkazai hogo gyōsei 埋蔵文化財の保存と活用一地域づくり・人づくりをめざす埋蔵文化財 保護行政), présente ainsi une longue série d'exemples sur l'utilisation des résultats de l'archéologie préventive à des fins de construction d'identité régionale.

La loi de Protection des biens culturels a longtemps été divisée en deux positions : d'une part, la rigoureuse protection des biens culturels sur la base d'un fonctionnement par autorisation et exception ; d'autre part, un fonctionnement moins outillé face à la destruction, qui appréhende le patrimoine enfoui en se reposant sur la déclaration de travaux ou de découverte. Plus exactement, seul le patrimoine enfoui était écarté du système de protection draconien offert aux autres biens culturels spécifiquement définis par la loi. Dans les révisions adoptées ces dernières années, cette distinction se vide de sens puisque l'objectif consiste désormais à étendre le périmètre de la protection culturelle, par des mesures flexibles susceptibles de recueillir la compréhension et le soutien spontanés du public ${ }^{16}$, comblant ainsi le fossé entre la sauvegarde et la destruction. Fortement dépendantes de leur fonctionnement décentralisé, les administrations de la culture n'ont d'autre choix que de se transformer en empruntant des dispositifs qui, tout en continuant à restreindre la façon de disposer du patrimoine, donnent en même temps de la souplesse quant à sa désignation ou sa découverte. En ce sens, on peut considérer que le système aura terminé sa modernisation lorsque sa flexibilité aura évolué au point de permettre au

16. Le soutien des populations locales à la protection du patrimoine en général, et de celui des sites archéologiques en particulier, est un élément fondamental du bon fonctionnement du dispositif de protection japonais actuel. Ce soutien est souvent décisif dans la sauvegarde d'un site ou sa destruction totale lors de travaux d'aménagement. On se reportera, par exemple, au cas relativement récent et parfaitement illustratif du devenir du site archéologique protohistorique de Muki-Banda (Inada 2008). 
patrimoine enfoui de devenir naturellement une catégorie à part entière au sein de l'article 2 de la loi de Protection des biens culturels.

Traduit du japonais et annoté par Laurent Nespoulous

\section{Bibliographie}

\section{Bunkachō kinenbutsu-ka 文化庁} 記念物課 2005

Nōrin suisan-gyō ni kanren suru bunkateki keikan no hogo ni kan suru chōsa kenkyū hōkokusho 農林水産業に関連する 文化的景観の保護に関する調査研究 報告書 (Étude relative à la protection des paysages culturels liés aux activités de productions agraires, forestières et aquatiques).

\section{Bunkachō maizōbunkazai hakkutsu chōsa taisei tō no seibi jūjitsu ni kan suru chōsa kenkyū iinkai \\ 文化庁埋蔵文化財発掘調査体制等の整備 充実に関する調査研究委員会 2007 \\ Maizō bunkazai no hozon to katsuyō. Chiikizukuri, hitozukuri o mezasu maizō bunkazai hogo gyōsei 埋蔵文化財の保存 と活用一地域づくり・人づくりをめざす埋蔵 文化財保護行政 (Le Patrimoine enfoui, sa conservation et sa valorisation. Pour une administration des biens culturels enfouis centrée sur l'autonomie et le dynamisme des régions et de leurs populations).}

\section{Bunkachō dentō bunka-ka}

文化庁伝統文化課 2004

«Bunkazai hogō-hō no ichibu kaisei

ni tsuite. Kokumin seikatsu ni mijikana

bunkazai ni tai suru hogo no kakudai »

文化財保護法の一部改正について一国民

生活に身近な文化財に対する保護の拡大

(Au sujet de la révision partielle de la

loi de Protection sur les biens culturels.

De l'élargissement du périmètre

de la protection des biens culturels

intimement liés au quotidien des citoyens), Gekkan bunkazai 月刊文化財

(Revue mensuelle des biens culturels), 491 : 42-47.

\section{DEMOULE Jean-Paul}

\& SOUYRI Pierre-François (dir.) 2008

Archéologie et Patrimoine au Japon, Paris, MSH.

INADA Takashi 稲田孝司 2008

« Lois, administrations et mouvements pour la protection des sites archéologiques au Japon », in Jean-Paul Demoule \& Pierre-François Souyri (dir.) 2008, Archéologie et Patrimoine au Japon, Paris, Éditions de la Maison des sciences de I'homme : 119-132. 


\section{INADA Takashi 2014}

Nihon to Furansu no iseki hogo. Kōgaku to hō, gyōsei, shimin undō 日本とフランスの 遺跡保護 考古学と法、行政、市民運動 (La protection des sites achéologiques au Japon et en France. L'archéologie, les lois, les institutions et la mobilisation citoyenne), Tokyo, Iwanami shoten 岩波書店.

SHIINA Shintarō 椎名慎太郎 1977 Seisetsu bunkazai hogo-hō 精説文化財保護法 (L'esprit de la loi de Protection des biens culturels), Shin Nihon hōki shuppan kabushiki gaisha 新日本法規出版株式会社. 